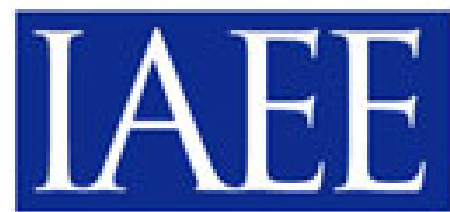

WWW.IAEE.ORG

INTERNATIONAL

ASSOCIATION for

ENERGY ECONOMICS

Reactive Power is a Cheap Constraint

Author(s): Edward Kahn and Ross Baldick

Source: The Energy Tournal, Vol. 15, No. 4 (1994), pp. 191-201

Published by: International Association for Energy Economics

Stable URL: http://www.jstor.org/stable/41322572

Accessed: 19/09/2014 13:11

Your use of the JSTOR archive indicates your acceptance of the Terms \& Conditions of Use, available at http://www.jstor.org/page/info/about/policies/terms.jsp

JSTOR is a not-for-profit service that helps scholars, researchers, and students discover, use, and build upon a wide range of content in a trusted digital archive. We use information technology and tools to increase productivity and facilitate new forms of scholarship. For more information about JSTOR, please contact support@jstor.org.

International Association for Energy Economics is collaborating with JSTOR to digitize, preserve and extend access to The Energy Journal. 


\title{
Reactive Power is a Cheap Constraint
}

\author{
Edward Kahn* and Ross Baldick**
}

Hogan (1993) has proposed a version of marginal cost pricing for electricity transmission transactions that include a component for reactive power to support voltage at demand nodes. His examples support the notion that the cost of satisfying voltage constraints can be quite high. We show that in his simplest example the price on this constraint results from an uneconomic and artificial characterization of the problem, namely an inefficient and unnecessarily constrained dispatch. By eliminating this characterization, the price of reactive power falls to a very modest level. Our counterexample has implications for the institutional arrangements under which transmission pricing reform will take place. We believe that environment will be an open access competitive setting, where dispatch is still controlled by one group of participants. Manipulation of marginal transmission costs becomes quite feasible in complex networks through subtle changes to dispatch. Therefore an open access regime using marginal cost pricing must involve either some kind of monitoring and audit function to detect potential abuses, or alternatively, institutional restructuring to eliminate conflicts of interest.

\section{INTRODUCTION}

Increasing reliance on market forces in electricity has focused attention on the crucial role of the transmission network. Unlike other network systems in natural gas, telecommunications or airlines, the electricity network is subject to real time physical constraints for which intuition is difficult to develop. Proposals to re-align the pricing and access conditions for electricity transmission must confront these physical constraints and treat them appropriately. The electrical engineering literature is replete with discussions of specific reliability problems that result in operational limitations on the use of the high voltage network (Stoll, 1989). In this paper, we focus on one widely applicable constraint, the limits of transmission line loadability due to voltage limits. Voltage limits are difficult for non-engineers, in part because there is an

The Energy Journal, Vol. 15, No. 4. Copyright ${ }^{\circ} 1994$ by the IAEE. All rights reserved.

* Lawrence Berkeley Laboratory, Bldg. 90 Rm 4000, Berkeley, CA 94720, USA.

** Department of Electrical \& Computer Engineering, University of Texas, Austin, TX 78712. 


\section{2 / The Energy Journal}

abundance of terminology for the same things. For example, reactive power is the quantity that is said to be lacking when voltage is insufficient due to generator, transmission or load characteristics. Berg et al., (1983) is a good discussion from an economist's point of view.

Engineers use the term "loadability" instead of capacity for transmission lines to reflect the operational effect of constraints on facility usage. For high voltage lines of 50 to $\mathbf{3 0 0}$ miles in length, voltage limits are the predominant constraint (Dunlop et al., 1979). In the economics literature, voltage limits have been discussed recently in the context of a particular transmission pricing proposal known as spot, locational or node pricing (Hogan, 1992,1993; Schweppe et al., 1988; Baughman and Siddiqi, 1991). We address our discussion to Hogan's exposition.

The basic notion underlying the node pricing approach is that in an optimally dispatched network the cost differences between different nodes in the grid reflect the value of transmission. If there is abundant transmission capacity between two points, the node prices should reflect only incremental losses. Where congestion occurs, differences in marginal generation costs between nodes also reflect the value of the congestion constraint. The effect of loadability limits is a particular form of congestion, which Hogan and others suggest should be included in the pricing. Where voltage limits are operative, this means putting a price on these limits. Hogan (1993) presents the case for such a price. His principal argument for this proposal is a series of increasingly complex examples which show that the voltage constraint has a high value.

In this paper we examine Hogan's simplest example of a voltage constraint, based on a three node network. We show that this example violates the fundamental assumption of all the node pricing literature, namely that the network is optimally dispatched. We illustrate this problem by showing a lower cost dispatch that meets the same constraint. We use these examples to call into question the claim that node pricing can be implemented under current institutional arrangements. That is, while we agree with node pricing for short run allocation under the assumptions of information symmetry amongst participants and of infinite available computing resources, we question its practicality under prevailing institutional arrangements in the U.S. ${ }^{1}$ As the electricity industry in the U.S. is organized today, it is extremely difficult to know if a particular dispatch pattern is optimal, or if it reflects the presence of artificial constraints. The problem of information asymmetry in electricity transmission is profound and must be addressed in the arrangements for pricing and managing an open access regime. 


\section{HOGAN'S EXAMPLES ARE NOT GENERIC}

To argue for the importance of reactive power pricing, Hogan uses examples of two kinds. The first is a simple triangular arrangement of lines with two generation nodes (numbered 1 and 2) and one load node (numbered 3). Generation is cheaper at Node 1 than at Node 2. There are three links in this network: from 1 to 2,2 to 3 , and 1 to 3 . The link from 1 to 3 is the limited capacity line; the limit is due to low voltage at Node 3. This limit forces generation to the higher cost location at Node 2. Figure 1 shows this configuration, using Hogan's representation of his voltage constrained case (this corresponds to his Figure 7). The purpose of using this simplest possible network topology is to illustrate basic phenomena in a pedagogic fashion. Subsequent examples, based on a more complex 38 node system are intended to show that the same qualitative phenomena illustrated in the simple case also appear in more realistic configurations.

Figure 1. Hogan's Example: Loadflow

(Real Power in MW, Reactive Power in MVar) (Voltage\} [Real Power Price, Reactive Power Price]

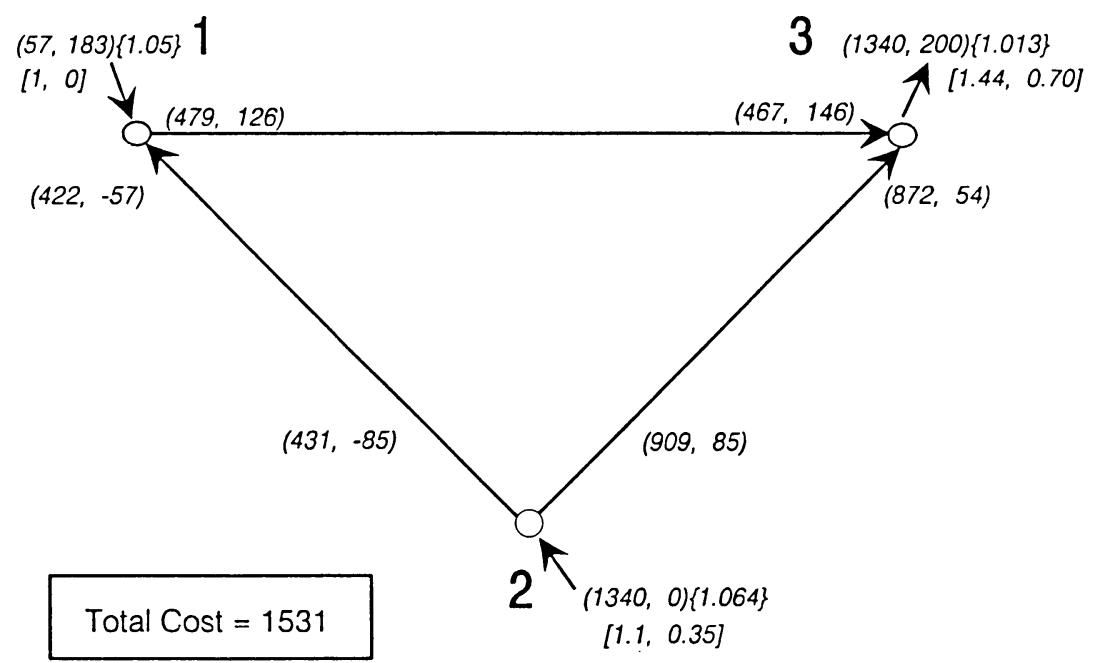

In Figure 1 a minimum voltage at Node 3 is specified. It is also common practice to specify maximum voltages. For the purposes of this initial discussion, we treat the voltages in Figure 1 as reliability requirements, and seek to replicate them. To reproduce the results in Figure 1 , we use the same network parameters used by Hogan. These are given in our Appendix. Using 
these parameters, and fixing generation at Nodes 1 and 2 as in Figure 1, we reproduce the line flows and voltages specified there. We performed these calculations using standard power flow software, which is readily available in a number of packages, and obtained Hogan's results to within round-off errors.

It is important to notice that the generator at Node 2 produces no reactive power, even though the load point (Node 3) consumes 200 MVAr. We do not believe that there is a good reason for restricting reactive power production at Node 2 . Such a restriction is artificial since generators produce the bundled product of both real and reactive power. There is a substitution between these components of the bundled product, i.e. more reactive power means less real power capacity, but in this case that is exactly what is required. ${ }^{2}$ By producing reactive power at Node 2, the voltage at Node 3 would be supported, allowing less reactive power production and more real power production at Node 1. If there is some other constraint limiting reactive power production at Node 2 , then we do not have a voltage constraint, but some other kind of constraint. An example of this would be a stability limit. Since there is no indication of this in Hogan's discussion, then nothing should limit the more efficient dispatch strategy. Such a dispatch strategy will relieve the constraint on power flow over the line from Node 1 to Node 3, and lower the total cost by shifting generation to Node 1. Our calculations show that a very substantial shift of this kind is possible.

Before illustrating the effect of removing the artificial constraint on reactive power at Node 2, we must discuss Hogan's pricing algorithm. The basic theory of node pricing derives these prices from a formal optimization process. The power flow program used to produce Figure 1 does not produce such prices directly. Hogan describes a procedure he uses to derive prices from a power flow. We adopt the more natural procedure of embedding the problem in an optimal power flow framework. Optimal power flow (OPF) is a more complex calculation than ordinary power flow because it involves a simultaneous minimization of fuel costs along with satisfying the ordinary power flow constraints (Burchett et al., 1982; Gribik et al. 1991). OPF is not widely available in software packages. We used a research grade implementation developed at the University of Texas-Austin, which is adequate for our small network.

Figure 2 shows the results of running the OPF subject to the following constraints: (1) voltage at node 1 is 1.05 , (2) voltage at node $3 \geq 1.013$, (3) voltage at node $2 \leq 1.064$, and (4) reactive power production at node 2 is zero, and (5) line 1 to 3 flow $\leq 600$ MVA. This figure includes the real and reactive power prices at each node. We adopt Hogan's assumption that the cost of power at node 1 is one monetary unit and the cost at node 2 is 1.1 monetary units. The

2. This substitution is described in Stoll (1989) and Berg et al. (1983), for example. 
dispatch results differ marginally from Figure 1; slightly more real power is produced at Node 1 and less at Node 2. The result is a slightly lower total cost; 1523 units in the case of Figure 2 compared to 1531 in Figure 1. The prices of real and reactive power at node 3 are quite similar to Hogan's results, 1.43 for real power and 0.67 for reactive power.

\section{Figure 2. Hogan's Example: OPF}

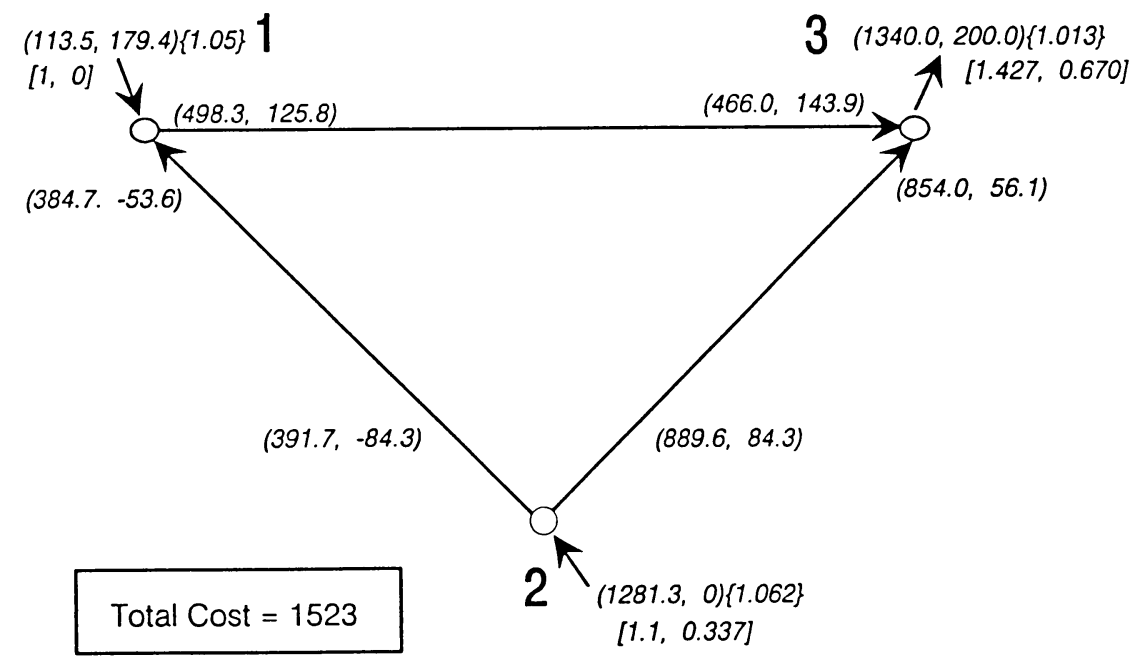

\section{A COUNTER EXAMPLE}

Next, we remove the artificial constraint on reactive power production at node 2. This will mean less real power produced at this node due to the real/reactive power trade-off at a generator. But since node 2 production is expensive, this is consistent with economic dispatch without other constraints. The results are shown in Figure 3.

This case shows much larger changes in dispatch, total cost and prices at Node 3 compared to Hogan's results and Figures 1 and 2. Between Figure 2 and Figure 3, real power production at Node 2 declines by $337 \mathrm{MW}$. The increase at Node 1 is $329 \mathrm{MW}$, indicating that real losses have decreased. Total cost declines by 42 monetary units, or nearly $3 \%$. The real power price at Node 3 falls from 1.43 to 1.31 . The most dramatic change, however, is the reactive power price. It is now 0.04 compared to 0.67 in Figure 2 . With the artificial constraint on reactive power removed, its value falls down to a level that is not large. 
Figure 3. No Constraint on Reactive Power at Node 2: OPF

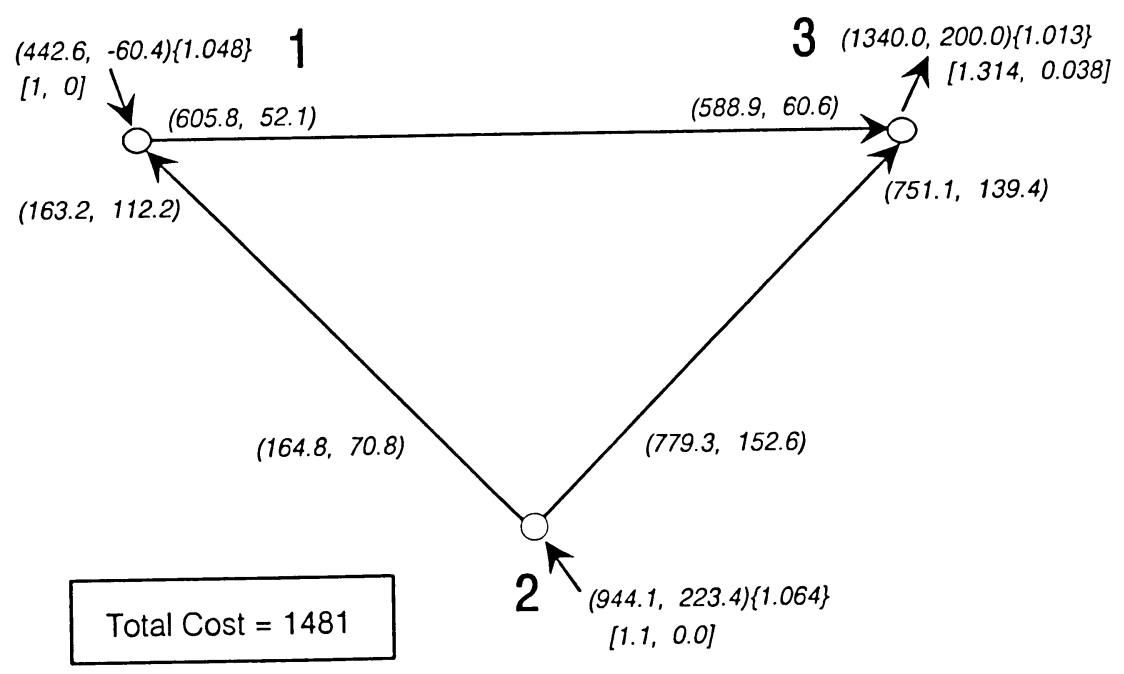

We believe that Figure 3 represents a far more generic situation in power systems than either Figures 1 or 2 . Generators that are close to the load are typically older and less efficient than newer remote units. It is cheap to shift production at these sites from real to reactive power to allow increased production from the remote efficient units. This practice of "dispatching VArs close to the load" is referred to briefly in Hogan's exposition, but it is contradicted by his examples.

In the case where there is insufficient reactive power available from generators that are close to the load, there are various planning solutions available to relieve voltage constraints. We briefly review how the voltage constraint appears in the contingency planning framework in the next section, and then discuss it from the planning perspective in the section after that.

\section{OPERATION UNDER CONTINGENCY}

The previous analysis is entirely static. It abstracts from the operating and reliability procedures typically used by power system engineers. Those procedures emphasize the operating responses that should be employed when an outage contingency occurs on the bulk power network. Nedwick, Mistr and Croadsale (1994) is a recent discussion of these issues that addresses reactive power constraints. That paper represents the design and operating philosophy of 
Virginia Power, and reflects their recent experience with some extreme operating conditions.

The basic approach these engineers take to reactive power planning is to use generating units as "reactive power reserve" for contingencies, and to supply all reactive requirements under normal operating conditions using low cost capacitor banks. The result is that generators may not produce much reactive power under normal conditions, but they are available to produce it in substantial quantities very quickly in emergencies. These procedures may look like a constraint on reactive power production in normal operation. That interpretation, however, is incorrect, and would not support what we have called the artificial constraint on reactive power at Node 2 in Hogan's example. The correct understanding of these dynamic procedures in a setting such as this is that there would be no net reactive demand at Node 3 to be supplied by generators, because it would all be met locally with capacitors. If somehow there was still such a demand, operating the units at Nodes 1 and 2 would not involve the asymmetric imposition of a reactive power constraint at only Node 2. As argued in Section 2, any special constraint on reactive power at Node 2 would have to arise from some other factor, such as a stability limit. In that case, we don't have a reactive power constraint, but we really have a stability constraint.

It is worth commenting briefly about the style of analysis embodied in Figures 1-3. By characterizing the voltage problem as a static load flow, it is possible to compute shadow prices. In the dynamic, i.e. contingency planning, setting in which these problems typically arise, it is not nearly so simple a matter to compute a shadow price. As a practical matter, we know of no commercially available software to perform OPF under contingency, even for simple problems such as the three node cases we have examined here. Therefore, the match between the actual engineering problem and the pricing problem is highly stylized. While such stylizations can be useful, they lose all meaning if the wrong constraints get embedded in their formulation.

\section{REACTIVE POWER IS ALSO CHEAP IN THE PLANNING DOMAIN}

Baldick and Kahn (1993b) use a triangle model much like the previous examples to analyze a voltage limited transmission constraint from the planning perspective. That analysis is motivated by a real case in which a large regional utility is proposing to reinforce a constrained transmission corridor. The transfer capacity over the corridor is limited by voltage minima under line outage contingencies (APCo, 1991). In the general case, where an increase in demand at the load center can be met by generation at a low cost remote node, at a higher cost intermediate node, or by the most expensive generation at the load, optimal choices depend on trade-offs involving the differences in generation 


\section{8 / The Energy Journal}

costs between sites, the cost of added transmission capacity, and the cost of reactive power compensation equipment. As we have indicated, reactive power capacity is available from an electric generator in addition to real power: generators produce the bundled product of real and reactive power. Additional reactive power can also be produced as a single product by compensation equipment such as capacitors.

There is a wide range of reactive power compensation equipment from low cost fixed capacitors to more expensive devices known as static VAr compensators. The capital cost of such equipment is typically no more than $\$ 50 / \mathrm{kV}$, and the operating cost is minimal. This is roughly $1 \%$ of the lifecycle costs of baseload electric generation. Each kVA of local reactive power generation typically relieves transmission capacity from a remote generator by between 0.3 and $1 \mathrm{~kW}$, depending upon many issues including load power factor (Stoll, 1989; Baldick and Kahn, 1993b).

Voltage limits can be relieved by compensation equipment only up to the minimum of the stability and thermal limits on the capacity of transmission lines. If remote generation is very much cheaper than local alternatives and transmission is already fully compensated, then transmission reinforcement may be appropriate. Costs of new high voltage transmission lines are on the order of $\$ 1 / \mathrm{kW}$-mile, so a 200 mile line (roughly appropriate for the voltage limited case) would cost $\$ 200 / \mathrm{kW}$. Other types of reinforcement may be more or less expensive. For example, estimates made by the Southern California Edison Company (1993) are seldom in excess of $\$ 300 / \mathrm{kW}$, and more frequently less than $\$ 100 / \mathrm{kW}$, depending on location.

Finally, there are cases in which the cost differences between remote and local generation may be on the order of $\$ 100-300 / \mathrm{kW}$. In such cases, higher cost local generation may be preferable to remote generation, when the voltage support benefits are appropriately assessed. If we assume that the high end of this range is a high estimate of the costs of the reactive power constraint, this would still be only about $6 \%$ of the lifecycle cost of baseload generation.

Knowing which option is preferable in individual cases requires detailed study. Lumpiness in both generation and transmission capacity will complicate economic analysis (Baldick and Kahn, 1993a). Broadly speaking, however, the alternatives for relieving voltage constraints are abundant and not expensive. The examples offered by Hogan where the reactive power constraint is $70-300 \%$ of real power costs is one to two orders of magnitude too high. As we have shown by our counterexample in Section 3, these estimates may indicate more that the grid is sub-optimally dispatched rather than that voltage constraints are expensive. 


\section{INFORMATION PROBLEMS AND INSTITUTIONAL STRUCTURE}

The point of these examples is that even in simple cases transmission costs are complex. In real networks, there is an enormous asymmetry in information between the transmission owner and any other party. This applies to potential competitors, customers, and regulators. In the "club" system of network co-ordination among transmission owning utilities, there is an information equilibrium of checks and balances that prevents one utility from exploiting others. This is described by Walton (1993) with particular reference to planning procedures in the Western Systems Coordinating Council. An open access regime, however, introduces more competition. This creates conflicts of interest between the transmission owner and wholesale competitors. Experience with such competition where dispatch and operating issues are concerned shows that information manipulation through the vehicle of complex computer models is a standard part of the strategic gaming ( $\mathrm{Kahn}$, to appear).

Since node pricing is proposed for use in a competitive open access system, there is some question about whether the optimality claims of such a pricing arrangement will be realized in practice. Hogan (1992) suggests that implementation of node pricing need not require any change in current institutional arrangements. Others, such as Frame (1992), who does not endorse this method, question whether this is the case. Ruff (1994), who does endorse node pricing, appears to recognize that restructuring institutions will be required to implement this kind of market.

Our examples show why an audit function must be part of any node pricing arrangement absent any more complete restructuring. They also argue for joint planning arrangements. Audit is necessary to detect cases such as those illustrated by Figures 1 and 2, where operating procedures that are inefficient result in high marginal price signals that do not reflect true scarcity or congestion. Whereas the artificial constraint was relatively easy to detect in the simple three node system, it would be much more difficult to detect such constraints in a realistic system. Joint planning arrangements at the regional level, with full participation by independent producers and consumers, might also help to detect global inefficiencies that result from sub-optimization at the individual control area level.

Federal Energy Regulatory Commission (FERC) implementation of the Energy Policy Act will go part of the way toward addressing these issues. In particular, the Final Rule on transmission information requires utilities to provide extensive transmission system information and marginal generation cost data (not disaggregated by location) (FERC, 1993a). To create genuine checks and balances, however, information must be used in a setting that can discipline behavior. The most promising alternative for such a setting is the notion of a Regional Transmission Group (RTG). There has been much discussion of RTGs 
as an information exchange/dispute resolution forum where all interested parties could negotiate matters of common concern. The tasks facing such organizations are formidable (Kahn, 1994), including satisfying FERC that they are behaving appropriately (FERC, 1993b). It is not clear whether RTGs might evolve toward providing the kind of wholesale electricity institutions needed for an efficient open access regime. Others have argued that non-discriminatory treatment of operating constraints under open access will require a major restructuring (Graves et al., 1993). Open access in electricity transmission will require an unbundling and examination of the entire electricity cost structure so that agreement about the true costs of complex constraints can be reached. Existing institutions may well not be adequate to this task.

\section{APPENDIX}

The network parameters used are given in per unit with respect to a base of 100 MVA and 1.0 per unit V (Bergen, 1986). Each of the three lines has the parameters given in the table.

Table 1. Electrical Parameters for Triangle Examples

\begin{tabular}{llll}
\hline Series Parameters & \multicolumn{3}{c}{ Shunt Parameters } \\
\hline Resistance (R) & $\begin{array}{l}\text { Inductive } \\
\text { Reactance (X) }\end{array}$ & Conductance (G) & $\begin{array}{l}\text { Capacitive } \\
\text { Susceptance (B) }\end{array}$ \\
& 0.010 & 0.000 & 0.400 \\
\hline
\end{tabular}

\section{ACKNOWLEDGEMENTS}

We would like to thank William Hogan and Fred Mistr for extensive discussion. We also thank Martin Baughman and Shams Siddiqi of the Center for Energy Studies at the University of Texas, Austin for the use of OPF software. This research was partially supported by the Assistant Secretary for Energy Efficiency and Renewable Energy, Office of Utility Technologies, Office of Energy Management of the U.S. Department of Energy under Contract No. DE-AC03-76SF0098 and the Universitywide Energy Research Group of the University of California.

\section{REFERENCES}

Appalachian Power Company (APCo) (1991). Case Number PUE910050 Before the State Corporation Commission of Virginia, Appendix, Volume 1. 
Baldick, R. and E. Kahn (1993a). "Network Costs and the Regulation of Wholesale Competition in Electric Power." Journal of Regulatory Economics 5(4):367-384.

Baldick, R. and E. Kahn (1993b). The Transmission Interface Constraint Problem, Lawrence Berkeley Laboratory Report, LBL-34772.

Baldick, R., J. Kaye and F. Wu (1992). "Electricity Tariffs Under Imperfect Knowledge of Participant Benefits." IEEE Transactions on Power Systems 7(4):1471-1482.

Baughman, M. and S. Siddiqi (1991). "Real Time Pricing of Reactive Power: Theory and Case Studies." IEEE Transactions on Power Systems 6(1):23-29.

Berg, S., J. Adams and B. Niekum (1983). "Power Factors and the Efficient Pricing and Production of Reactive Power." The Energy Joumal 4 (Special Electricity Issue): 93-102.

Bergen, A. (1986). Power Systems Analysis. Prentice Hall.

Burchett, R., H. Happ and K. Wirgau (1982). "Large Scale Optimal Power Flow." IEEE Transactions on Power Apparatus and Systems PAS-101(10): 3722-3732.

Dunlop, R., R. Gutman and P. Marchenko (1979). "Analytical Development of Loadability Characteristics for EHV and UHV Transmission Lines. " IEEE Transactions on Power Apparatus and Systems PAS-98(2):606-617.

Federal Energy Regulatory Commission (FERC) (1993a). Final Rule in Docket No. RM93-10.

Federal Energy Regulatory Commission (FERC) (1993b). Policy Statement in Docket No. RM93-3.

Frame, R. (1992). Transmission Access and Pricing: What Does a Good "Open Access" System Look Like?, NERA Working Paper 14.

Graves, F., P. Carpenter, M. Ilic, and A. Zobian (1993). "Pricing of Electricity Network Services to Preserve Network Security and Quality of Frequency Under Transmission Access." Response to the Federal Energy Regulatory Commission's Request for Comments in its Notice of Technical Conference Docket No. RM93-19-000.

Gribik, P., D. Shirmohammadi, S. Hao, C. Thomas (1990). "Optimal Power Flow Sensitivity Analysis." IEEE Transactions on Power Systems 5(3):969-976.

Hogan, W. (1992). "Contract Networks for Electric Power Transmission." Journal of Regulatory Economics 4(3):211-242.

$\rightarrow$ Hogan, W. (1993). "Markets in Real Electric Networks Require Reactive Prices." The Energy Journal 14(3):171-200.

Kahn, E. (1994). "Regional Transmission Groups: How Should They Be Structured and What Should They Do?" From Regulation to Competition: New Frontiers in Electricity Markets. ed. M. Einhorn, Norwell, MA: Kluwer Academic Publishers: 237-255.

Kahn, E. "Regulation by Simulation: The Role of Production Cost Models in Electricity Planning and Pricing." Operations Research (to appear).

Nedwick, P., A. Mistr and E. Croasdale (1994). "Reactive Management: A Key to Survival in the 1990s." IEEE Paper 94 SM 551-2 PWRS, 1994.

Ruff, L. (1994). "Stop Wheeling and Start Dealing: Resolving the Transmission Dilemma," The Electricity Journal 7(5): 24-43.

Schweppe, F., M.Caramanis, R. Tabors and R. Bohn (1988). Spot Pricing of Electricity. Norwell, MA:Kluwer Academic Publishers.

Southern California Edison Company (1993). Transmission Cost Tables modified to comply with CPUC D.92-09-078 et al.

Stoll, H. (1989). Least Cost Electric Utility Planning. New York: John Wiley and Sons.

Walton, S. (1993). "Establishing Firm Transmission Rights Using a Rated System Path Model." The Electricity Journal 6(8):20-33. 